\title{
Modeling the Labor Force Participation Rate of the Philippines through Multiple Linear Regression
}

\author{
Angelu G. Leynes a, Maidy V. Baquilar ${ }^{\text {b }}$ and Constantino H. Aniag ${ }^{\text {c }}$, Audie B. Oliquino ${ }^{\text {d }}$

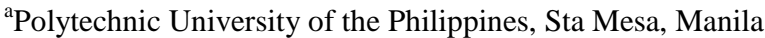 \\ ${ }^{b}$ Polytechnic University of the Philippines, Sta. Mesa, Manila \\ ${ }^{c}$ Polytechnic University of the Philippines, Sta. Mesa, Manila \\ ${ }^{\mathrm{d}}$ Faculty Member, Department \& Statistics, College of Science, Polytechnic University of the Philippines, Sta. Mesa, Manila \\ Corresponding Email: aag.leynes@ntc.edu.ph, ${ }^{b}$ maidybaq@gmail.com, ${ }^{c}$ tananiag@yahoo.com, daboliquino@pup.edu.ph
}

Article History: Received: 10 November 2020; Revised 12 January 2021 Accepted: 27 January 2021; Published online: 5 April 2021

\begin{abstract}
The main purpose of this study is to formulate a mathematical regression model showing the significant effect of the independent variables to the dependent variable. The researchers obtained the quarterly data from the Philippine Statistics Authority (PSA) limited only from 2001 to 2016 with a total of 448 observations. The data include the following factors: Employment Rate (X1), Underemployment Rate (X2), Gross National Income (X3), Household Population 15 yrs+ (X4) and Gross Domestic Product (X5) as independent variables that can affect the Labor Force Participation Rate in the Philippines. The researchers use the IBM Statistical Package for the Social Sciences as a statistical tool for recording and analyzing the quarterly data. The researchers employed two main statistical treatments which are subjected at $1 \%$ level of significance: Pearson R Correlation, to determine which of the independent variables have significant relationship with the dependent variable; and Multiple Linear Regression Analysis, to formulate the fitted mathematical model for the dependent variable. According to the results gathered, three out of five independent variables become the predictors of Labor Force Participation Rate which are included in the fitted model. Moreover, the researchers also utilize the Paired-T test to find if the predicted values and the actual values of the dependent variable have significant difference with each other
\end{abstract}

Keywords: Labor Force, Labor Force Participation Rate. Multiple Linear Regression, Normal Estimation Equation, Employment Rate

\section{Introduction}

In an article published by Investopedia, it states that the Labor Force Participation Rate measures an economy's active labor force and is the sum of all employed workers divided by the population of the working age.[1] According to Power Hedge in his article about Labor Force Participation Rate, he defines it as the number of people who are either employed or are actively looking for work. He also mentioned that several workers are often get discouraged and stop looking for employment, leading to a decrease in the labor participation rate during economic recession.[2] As for Hayes (2018), those people who are no longer actively searching for work not be included in the participation rate.[3]

According to Organization for Economic Cooperation and Development or OECD from their iLibrary, they stated that labor force participation rate is calculated as the labor force divided by the total working-age population. They also cited in their online library that the working age population refers to people who are 15 to 64 years old. In addition, this indicator is broken down by age group and it is measured as a percentage of each age group.[4]

Ofreneo cited in his article namely 'Jobless: Declining or Growing?' that in a robust economy with a productive population, an ideal Labor Force Participation Rate should be around 65 percent or more. He also mentioned that the LFPR trend in the Philippines had been hovering around 62-63 percent historically.[5]

This paper is made for the aim of formulating a fitted mathematical model using a normal estimation equation formed by Multiple Regression to forecast the Labor Force Participation Rate. This research also wants to determine the possible factors that are significant to the dependent variable. The researchers employ the five independent variables to test which among these variables can affect the dependent variable Labor Force Participation Rate. These are Employment Rate (X1), Underemployment Rate (X2), Gross National Income (X3), Household Population 15 yrs+ (X4) and Gross Domestic Product (X5). 


\section{Review Of Related Literature}

This area presents a review of related literatures that would be beneficial to the study summarized from previous writings and studies.

According to Joshua Montes in his study namely 'CBO's Projection of Labor Force Participation Rates', he mentioned that although most of the decline in the overall labor force participation rate comes from the aging of the baby-boom generation, other structural factors including the declining propensity of successive cohorts to participate in the labor market, the increase in disability insurance incidence, the declining male marriage rate, and monetary policy, have contributed most to the decline in this rate. [6]

On 2018, a paper entitled 'A Meta-Analysis of the Decline in the Labor Force Participation Rate', the researchers find evidence of covariation between wages and labor force participation, which is consistent with lagging wage growth discouraging workers from seeking employment. The association between wages and continued employment has been growing, suggesting increasing incentives to remain employed, but decreasing incentives to return to employment for those out of a job. They concluded that much of the decline in labor force participation may be related to the wage incentives associated with participation and entry in particular.[7]

The findings of the research entitled 'The Relationship Between Household Size, Real Wages, and Labor Force Participation Rates of Men and Women' show that while household size is negatively correlated with labor force participation rates for women, no such relationship exists for men. These results support the notion that traditional sex roles continue to exist in households related to market work. [8]

In the paper, 'Unemployment and Labor Force Participation: A Panel Cointegration Analysis for European Countries', they concluded that there is no cointegration between labor force participation and unemployment for males signaling that changes in unemployment rate don't alter the choices of males regarding participating the labor force. In other words, there seemed to be no proof for added worker or discouraged employee effect for males. [9]

A research titled as 'The Labor Force Participation Rate Trend and Its Projections' they construct the trend in the aggregate labor force participation rate and its projections over the next 10 years. They find out that 2000 and 2018 changes in the population composition substantially lowered the aggregate participation rate and its trend. The estimated rate is at its trend of $62.8 \%$, suggesting that the labor market is at full employment. They project that the trend will decline approximately 2.5 percentage points over the next decade. [10]

In January 2019, a study was conducted by Chad P. Bown and Caroline Freund about the problem of US Labor Force Participation. US labor force participation dropped sharply after workers faced long spells of unemployment in the wake of the financial crisis. As for the researchers, some workers turned to disability insurance, which aids people exiting the workforce, altering the incentives to remain employed. Workers out of the labor force and on disability have also become increasingly addicted to opiates in recent years, which is likely preventing them from reentering the labor force. [11]

According to Gaurang in his paper 'Trends and Factors Affecting to Female Labour Force Participation Rate in India', it has been found that Labor force participation rate, female ( $\%$ of female population ages $15+)$ has strong negative linear correlation with LN GDP (constant 2010 US\$), LN GDP per capita, PPP (constant 2011 international \$), School enrollment, tertiary, female (\% gross) and Literacy rate, youth female (\% of females ages 15-24). Results of regression analysis suggests that $87.9 \%$ variations in Labor force participation rate, female (\% of female population ages $15+$ ) in India are together explain by independent variables. [12]

In the research entitled 'Relationship between inflation, unemployment and labor force change rate in France: Cointegration test', the result of the analysis consists in a formal statistical confirmation of the existence of a unique linear and lagged relationship between inflation, unemployment and labor force change rate for the period between 1973 and 2004. [13]

The study titled as 'Factors Determining the Labour Force Participation Decision of Educated Married Women in a District of Punjab' conducted by Amtul Hafeez and Eatzaz Ahmad finds that the females' education level is robust and positive determinant of FLFP. Even so, monthly household income, number of workers in the household other than husband and wife and financial assets are significantly and reciprocally associated with it. Among the demographic factors, age and unit structure and size have an effect on the FLFP rate absolutely. [14]

In 2013, an article with a title 'Labor Force Dynamics: What Influences the Size of the Labor Force?' examined the varied influences on the scale of the labor force over a nine-year period. Higher levels of population and economic production induce higher working class size. Personal income levels and educational attainment positively influence on working class size, whereas cost of living inside a state is shown to own no impact. [15]

In the paper with a title 'An Analysis on the Unemployment Rate in the Philippines: A Time Series Data 
Approach', the researchers formulate a model to forecast the unemployment rate using SARIMA. Significant factors of unemployment rate are found to be Labor Force Rate and Population. Also, Population, GDP and GNI are shown to Granger-cause the dependent variable. These variables can affect the movement of the unemployment rate. [16]

In the study 'Modeling the Philippines' real gross domestic product: A normal estimation equation for multiple linear regression' only three independent variables are significant to the dependent variable namely: Consumers' Spending (x1), Capital Formation (x2) and Imports (x4), hence, can actually predict Real GDP (y). [17]

A research entitled as 'Regression Analysis of the Economic Factors of the Gross Domestic in the Philippines' formulate a mathematical model using a regression analysis. Capital Formation, Total Trade, Interest Rate, Exchange Rate and Unemployment Rate are found to be significant predictors of GDP. The said factors can explain GDP by $93 \%$. [18]

In this research with a title 'Modeling the Philippines' Exchange Rate: A Regression Analysis', the researchers revealed that only two independent variables are of significance to the dependent variables namely: interest rate (X1) and Labor force participation rate (X3) therefore; it can predict the Exchange rate (y) in the Philippines. The regression analysis shows that $83.5 \%$ (coefficient of determination) of the independent variable can predict the Dependent Variable. [19]

\section{Research Paradigm}

As shown in the research paradigm below, the researchers use the quarterly data of the independent and dependent variables from 2001 - 2016 as the input of the study. They develop a mathematical model using the multiple linear regression to identify the significant predictors to the dependent variable that can be used in predicting the future labor force participation rate which are the expected outputs of this paper.

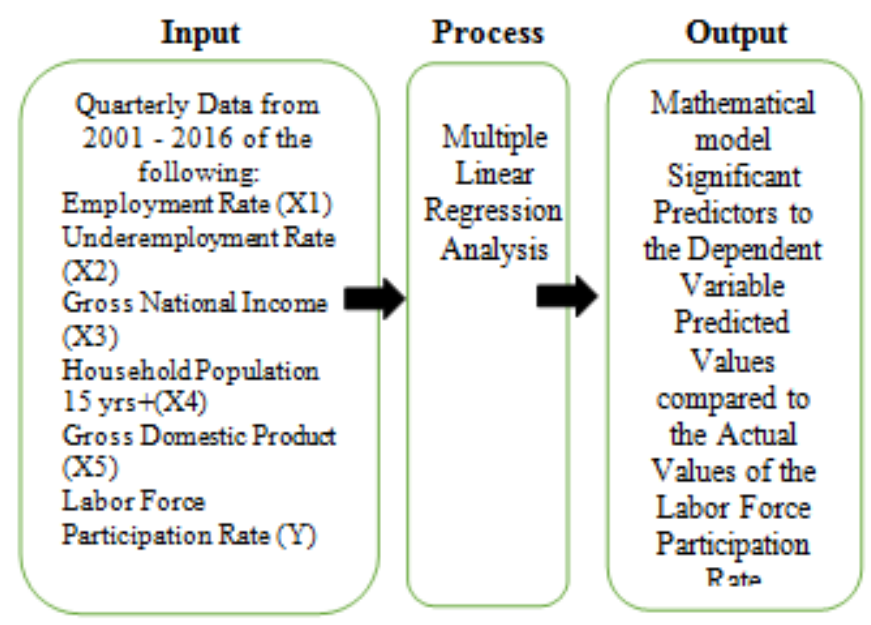

Fig. 1. Research Paradigm

\section{Objectives Of The Study}

The objective of this study is to formulate a mathematical model that can be used to predict the labor force participation rate using the Multiple Linear Regression Analysis and to identify the significant factors of the said variable. The factors that are considered as independent variables are Employment Rate (X1), Underemployment Rate (X2), Gross National Income (X3), Household Population 15 yrs+ (X4) and Gross Domestic Product (X5) that can possibly predict the dependent variable which is the Labor Force Participation Rate (Y).

\section{Scope and Limitations of the Study}

The scope of this study covers the quarterly data of independent variables including Employment Rate, Underemployment Rate, Unemployment Rate, Gross National Income, Household Population 15 yrs+, and Gross Domestic Product with the dependent variable Labor Force Participation Rate from 2001 up to 2016 with a total of 448 observations. The data were obtained from the website of Philippine Statistics Authority (https://psa.gov.ph/content/yearbook-labor-statistics-yls). 


\section{Significance of the Study}

The study would be beneficial to the researcher as the study would provide information that can help them on their field of study/program. This paper will enable them to apply what they have learned and enable them to learn and discover new findings relevant to their field of study.

Unemployment/underemployment worsen the circulation of the labor market and brings negative effects to the workers in the labor market The research could help the government in addressing these problems.

Lastly, this would also be beneficial to the Department of Education (DepEd), Commission on Higher Education (CHED) and Technical Education and Skills Development Authority (TESDA). Through the study, they can have knowledge on what field of study they should give more focus and attention as according to what the labor market demands in order to solve the problem of underemployment and unemployment.

\subsection{Statement of the Problem}

This study was conducted to develop a mathematical model through Multiple Linear Regression Analysis and to identify the significant predictors of the Labor Force Participation Rate. In particular, the researchers want to answer the following questions:

1. What is the behavior of the graph of the Labor Force Participation Rate (y) and the independent variables:

1.1 Employment Rate (x1)

1.2 Underemployment Rate (x2)

1.3 Unemployment Rate (x3)

1.4 Gross National Income (x4)

1.5 Household Population 15 yrs $+(x 5)$

1.6 Gross Domestic Product (x6)

2. Is there a significant relationship between the independent variables and the labor force participation rate?

3. Which of the independent variables are significant predictors of labor force participation rate?

4. What is the fitted model that shows the significant effect of the independent variables to the labor force participation rate?

5. Is there a significant difference between the actual value and predicted values of the labor force participation rate?

\section{Methodology}

\subsection{Statistical Tool}

IBM SPSS Statistics is a software package used for interactive, or batched, statistical analysis.[19] SPSS is great for opening data files, editing data such as computing sums and means over columns or rows of data, creating tables and charts containing frequency counts or summary statistics over (groups of) cases and variables, running inferential statistics such as ANOVA, regression and factor analysis and saving data and output in a wide variety of file formats.[20] The graphs and the tables of the study were generated from this software.

\subsection{Statistical Treatment}

\subsubsection{Pearson Correlation Coefficient ( $\mathbf{r})$}

Pearson Correlation Coefficient ( $r$ ) is a statistical test used to measure the strength of the association between the two variables.[21] The researchers use this test to determine if there are significant relationships between the independent variables and dependent variable. The formula for Pearson Correlation Coefficient $r$ is defined by:

$$
r=\frac{n \sum x y-\sum x \sum y}{\sqrt{\left\{n \sum x^{2}-\left(\sum x\right)^{2}\right\}\left\{n \sum y^{2}-\left(\sum y\right)^{2}\right\}}}
$$

\subsubsection{Multiple Linear Regression}

Multiple Linear Regression, defined by Kartik Singh (2018) is a statistical technique that uses several explanatory variables to predict the outcome of a response variable. The goal of multiple linear regression is to model the linear relationship between the independent variables and dependent variable. The formula for MLR is 
shown below:

$$
\gamma=\beta_{0}+\beta_{1} x_{1}+\beta_{2} x_{2}+\cdots+\beta_{p} x_{p}+\varepsilon
$$

where $\gamma$ is the dependent variable, $x$ is the independent variable, $\beta \_o$ is the $y$-intercept, $\beta$ are slope coefficients for each independent variable, and $\varepsilon$ is the error or also known as residuals.

The multiple regression model is based on the following assumptions: 1) There is a linear relationship between the dependent variables and the independent variables; 2) The independent variables are not too highly correlated with each other; 3) Residuals should be normally distributed with a mean of 0 and variance $\sigma$; 4) The residuals should be equally distributed across the regression line; and 5) No identifiable relationship exists between the values of the error term. [22]

\subsubsection{Paired Samples T Test}

Paired Samples T Test is a statistical test that compares two means that are from the same individual, object, or related units. The purpose of the test is to determine whether there is statistical evidence that the mean difference between paired observations on a particular outcome is significantly different from zero.[23]

$$
t=\frac{\bar{u}}{\sqrt{s^{2} / n}}
$$

\subsubsection{Measures of Forecast Accuracy}

Mean Absolute Deviation (MAD) is the sum of absolute differences between the actual value and the forecast divided by the number of observations. [24]

$$
\operatorname{MAD}=\frac{\sum_{t={ }_{1}}^{n}\left|A_{t}-F_{t}\right|}{n}
$$

Mean Square Error (MSE) is the sum of the squared error divided by the number of observations. [24]

$$
\operatorname{MSE}=\frac{\sum_{t=1}^{n}\left(A_{t}-F_{t}\right)^{2}}{n}
$$

Root Mean Square Error (RMSE) is the square root of the Mean Square Error. [24]

$$
\text { RMSE }=\sqrt{\frac{\sum_{t=1}^{n}\left(A_{t}-F_{t}\right)^{2}}{n}}
$$

Mean Absolute Percentage Error (MAPE) is the average of absolute errors divided by actual observation values. [24]

$$
\mathrm{MAPE}=\frac{\sum_{t=1}^{n}\left|\frac{A_{t}-F_{t}}{A_{t}}\right|}{n} \times 100
$$

\section{Results And Discussion}

This section will explain the behavior of the graph of the following independent variables and the dependent variables obtained from the first quarter of 2001 up to the fourth quarter of 2016. 


\section{A. Behavior of the Graph}
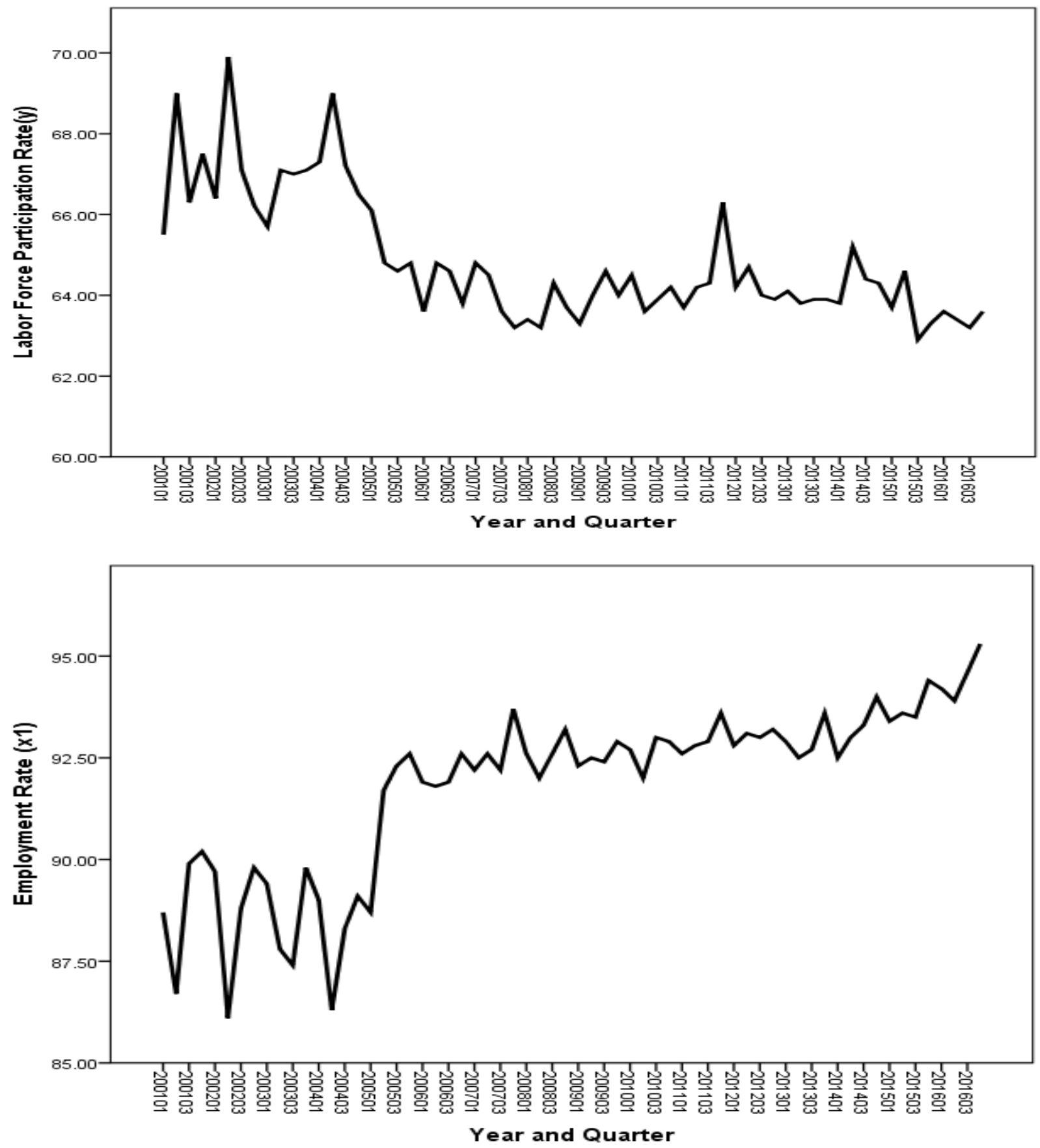

Figure 1. A) Quarterly Labor Force Participation Rate from 2001 - 2016. LFPR normally edge up during the 2nd quarter of 2002 due to the vacationing students looking for summer jobs. But this pattern was not observed in 2003 when the LFPR fell by 2.8 percentage points to 67.1 percent as roughly half a million persons dropped out of the labor force. In April 2014, LFPR was up again to 68.9 percent which is similar to the rate observed in the previous years. In nominal terms, the country's labor force increased from 34.635 million to 36.509 million. This translates to a year-on-year growth of 5.4 percent, the highest recorded since 2001. [25] Out of the estimated 66.6 million population 15 years old and over, 41.9 million persons were in the labor force in July 2015. This resulted to a labor force participation rate of 62.9 percent which was the lowest rate since 2001. [26] b) Quarterly Employment Rate from 2001 - 2016. The employment rate or the proportion of employed persons to total labor force was recorded at 95.3 percent in the 3rd quarter of 2016 and had its lowest during the 2nd quarter of 2004 at 86.3\%. [27] The conditions of labor and employment in the country have been improved based on the preliminary estimates of the Philippine Statistics Authority's (PSA's) Labor Force Survey in last quarter of the year 2016. [28] 

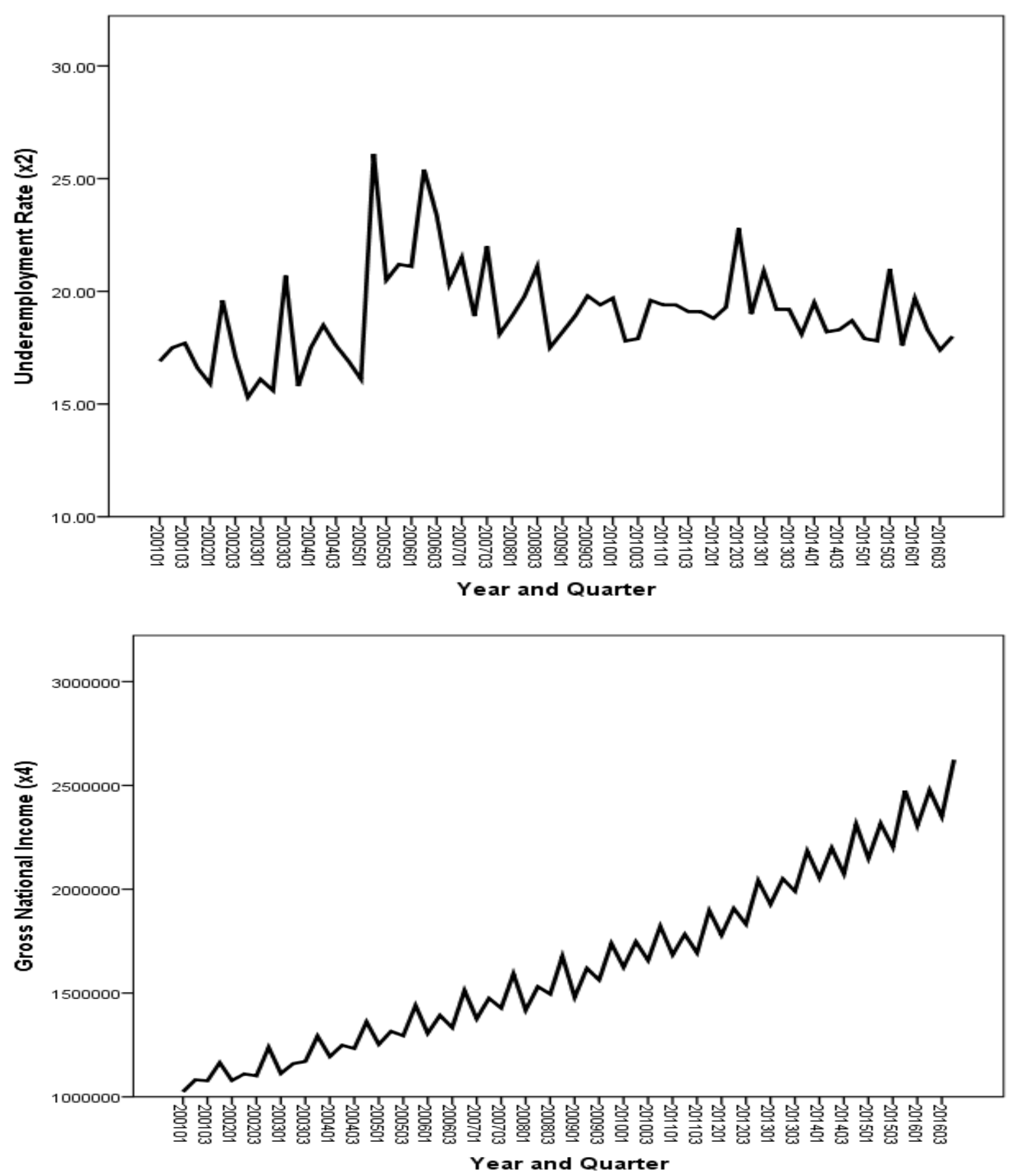

Figure 2.A)Quarterly Underemployment Rate from 2001 - 2016. In the Philippines, a person is underemployed if he/she is employed but declares himself/herself during the labor force survey that he/she desires to have additional hours of work in his/her present job, or to have a new job with longer working hours (Philippine Statistics Authority 2015). Although the unemployment rate has declined in recent years, there remains a relatively high underemployment rate, averaging around $20 \%$ since 2000. [29] In analyzing the Underemployment Rate, the graph shows fluctuating trend having its lowest point in the 4th quarter of 2002 and its highest point during the 2nd quarter of 2005. b) Quarterly Gross National Income from 2001 - 2016. 

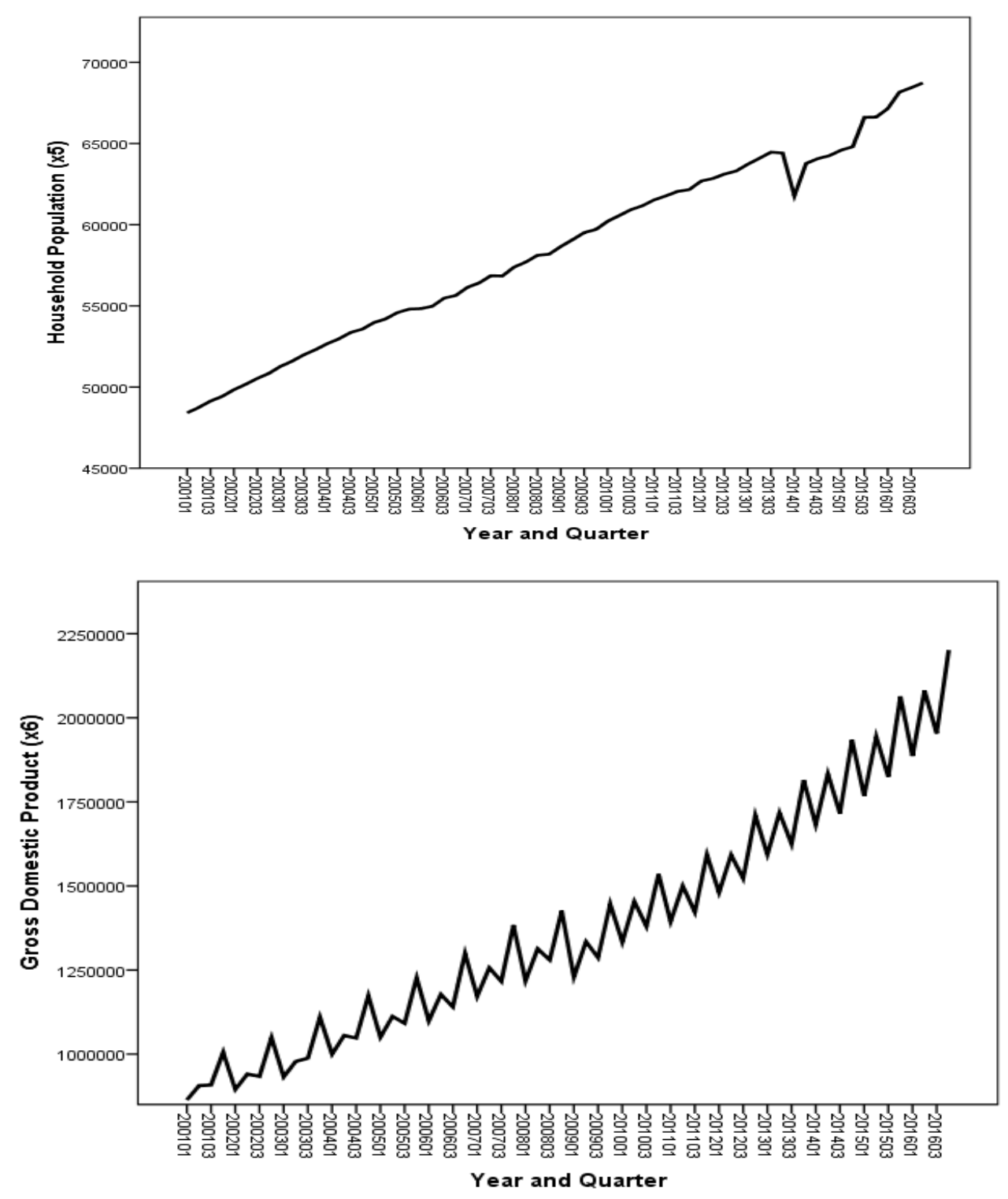


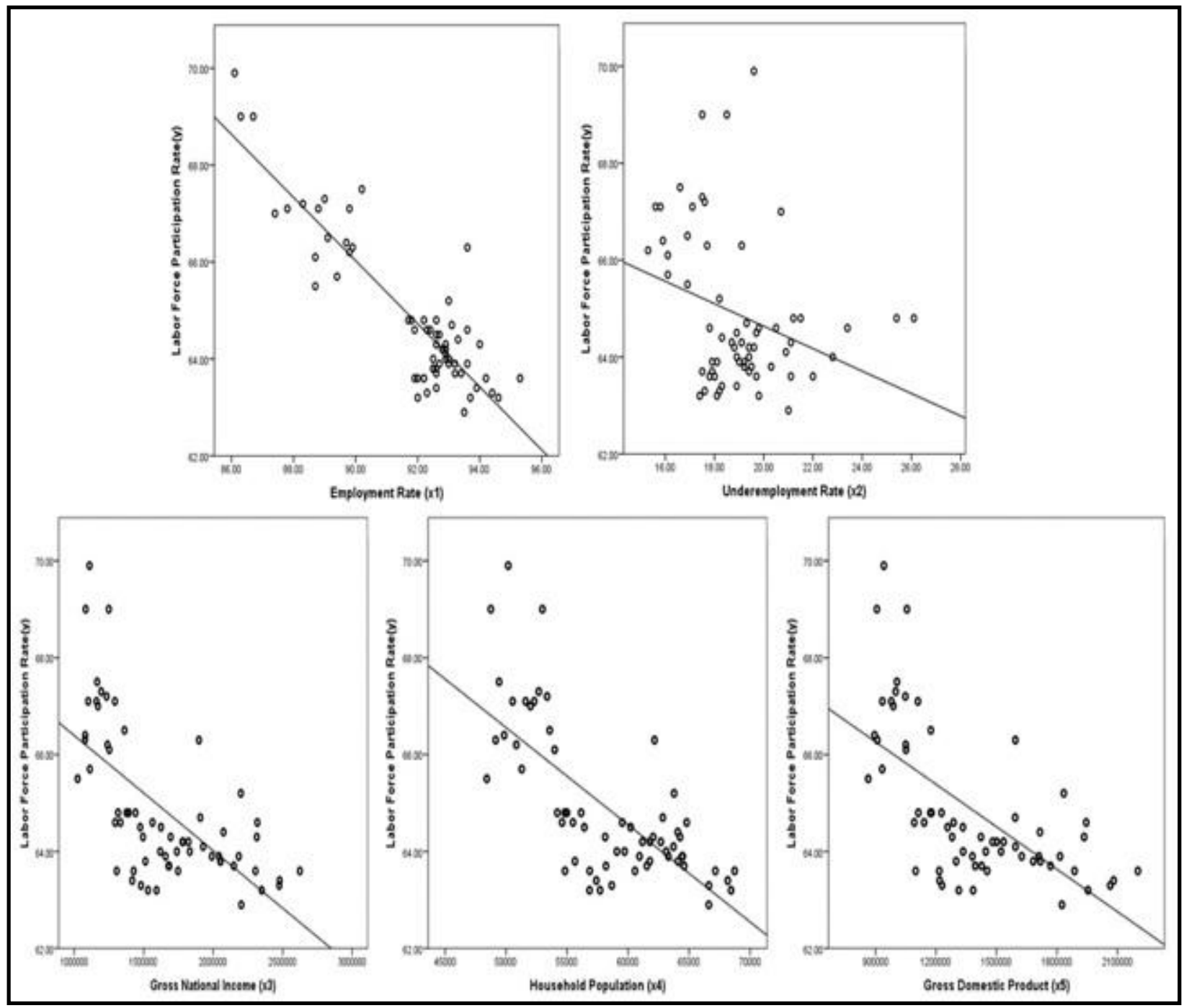

FIGURE 3. a) Quarterly Household Population from 2001 - 2016. b) Quarterly Gross Domestic Product from $2001-2016$.

\section{Conclusion And Recommendation}

This assessment to learning style is highly beneficial since the main focus of this study is the improvement of learning outcomes. On the part of the teacher, it will be an effective feedback on knowing students in a deeper level (Evans and Waring, 2006) and in so doing could adjust their teaching styles to suit individual needs. [18]

Furthermore, teachers should also take into consideration applying variety of strategies even if some has their own preferred learning style [19]. As what Hall and Mosley, Honigsfeld and Scheiring (2004); Sternberg et al., (2008) said, "When teachers have a better understanding on students learning styles, there is a high degree of effectiveness on instruction and assessment" [20] [21].

As shown in Figure 4 above, the scatterplot diagrams between the dependent and independent variables reveal the linear relationship between the dependent and independent variables. The more points cluster closely around the imaginary line of best fit, the stronger the relationship that exists between the two variables. It can be seen that Employment Rate, Underemployment Rate, Gross National Income Household Population 15 yrs.+ and Gross Domestic Product have downward trends indicating an inverse relationship with Labor Force Participation Rate, which means if the said variables will decrease, the Labor Force Participation Rate will increase. 
Table I:Pearson r Correlation of Labor Force Participation Rate (y)

\begin{tabular}{lllll}
\hline \hline & $\mathrm{r}$ & $\mathrm{p}$-value & Decision & Remarks \\
\hline Employment Rate(x1) & -0.887 & 0.000 & Reject Ho & Significant \\
Underemployment Rate (x2) & -0.308 & 0.013 & Reject Ho & Significant \\
Gross National Income(x3) & -0.635 & 0.000 & Reject Ho & Significant \\
Household Population 15 yrs (x4) & -0.717 & 0.000 & Reject Ho & Significant \\
Gross Domestic Product (x5) & -0.638 & 0.000 & Reject Ho & Significant \\
\hline \hline
\end{tabular}

\section{Legend: Correlation is significant at 0.01 level (2-tailed).}

In table 1, it shows that all independent variables have significant relationship to the dependent variable (y) at $1 \%$ level of significance. The Employment Rate (x1) has the value of 0.887 indicating that it obtained a very high correlation with the Labor Force Participation Rate (y). On the other hand, the Underemployment Rate (x2) has a low negative correlation with the dependent variable having the value of -0.308 .

Table II:Multiple Linear Regression of Labor Force Participation Rate (y)

\begin{tabular}{|c|c|c|c|}
\hline & Beta Coefficient & p-value & Remarks \\
\hline Employment Rate(x1) & 134.2993709 & 0.000 & Significant \\
\hline $\begin{array}{l}\text { Underemployment Rate } \\
\text { (x2) }\end{array}$ & -0.706655058 & 0.000 & Significant \\
\hline Gross National Income(x3) & 0.004811964 & 0.920 & Not Significant \\
\hline $\begin{array}{l}\text { Household Population } 15 \\
\text { yrs (x4) }\end{array}$ & 0.0000009 & 0.857 & Not Significant \\
\hline $\begin{array}{l}\text { Gross Domestic Product } \\
(\mathrm{x} 5)\end{array}$ & -0.0001494 & 0.043 & Significant \\
\hline
\end{tabular}

Legend: Correlation is significant at 0.05 level (2-tailed).

Based from the table 2, using the Multiple Linear Regression (Enter method), only two independent variables are significant predictors of labor force participation rate at $1 \%$ level of significance. These are Employment Rate (x1) and Household Population 15 yrs+ (x5). The Beta coefficients were obtained from the IBM SPSS Statistics.

\section{Model Through Normal Estimation Equation}

$\left[\begin{array}{cccc}64 & 5873.70 & 1215.20 & 3737928 \\ 5873.70 & 539359.89 & 111605.55 & 343699197.70 \\ 1215.20 & 111605.55 & 23351.64 & 71084893.80 \\ 3737928 & 343699197.70 & 71084893.80 & 220333651886\end{array}\right]\left[\begin{array}{c}\beta_{0} \\ \beta_{1} \\ \beta_{2} \\ \beta_{3}\end{array}\right]=\left[\begin{array}{c}4151.70 \\ 380838.62 \\ 78766.03 \\ 242075881.40\end{array}\right]$

$\beta_{\circ}=127.4465314 \beta_{1}=-0.685809473 \beta_{2}=-0.045934962 \beta_{4}=0.00002118319556$

The fitted model that shows the significant effect of the independent variables to the labor force participation rate is:

$\hat{y}=127.4465314-0.685809473 x_{1}-0.045934962 x_{2}+0.00002118319556 x_{4}$

Table III:Measures of Forecast Accuracy

\begin{tabular}{lllll}
\hline \hline & MAPE & MSE & RMSE & MAD \\
\hline Predictor & 0.8097 & 0.5124 & 0.7158 & 0.5273 \\
\hline \hline
\end{tabular}

Table IV:Significant Difference between Predicted Values and Actual Values of Labor Force Participation Rate

\begin{tabular}{ll}
\hline \hline Paired Sample t Test & p-value \\
\hline t statistic & 1.000 \\
\hline \hline
\end{tabular}

As shown in the table above, the predicted values are compared to the actual values of the dependent variable Labor Force Participation Rate (y) using the Paired Samples T-test. The researchers use this test to determine if there is a significant difference between the predicted values and actual values. The resulted $\mathrm{p}$-value is 1.000 which is greater than 0.01 , hence there is no significant difference between the predicted values and actual values of the dependent variable. Therefore, the significant factor can really affect the Labor Force Participation Rate (y). 


\section{Conclusion And Recommendation}

After having some statistical test and satisfying all the assumptions in Multiple Regression, the acquired Mathematical model reveals that three independent variables which are Employment (x1), Underemployment (x2) and Household Population 15 yrs $(\mathrm{x} 4)$ are the significant predictors to Labor Force Participation Rate (y). The model also indicates that there is no significant difference between the Predicted Values and the Actual Values of the dependent variable which means that the model is useful in estimating the Labor Force Participation Rate in the next 5 years.

Since there are three significant predictors out of six independent variables that can predict the Labor Force Participation Rate, the researchers suggest to add more factors such as Unemployment Rate, Population, Income, Educational Attainment, and Wages that can estimate the Labor Force Rate. The researchers also recommend to add more data in each variable to predict more accurately. The researchers also suggest to develop and implement programs for the factors that may help increase the Labor Force Participation Rate.

\section{References}

Robert Sternberg, The Importance of Understanding Individual Learning Styles, URL: https://www.ernweb.com/educational-research-articles/the-importance-of-understanding-individual-learningstyles/, date retrieved: March 18, 2018

Onofre, Serious Problems with the K-12 Senior High School Curriculum, URL: https://taborasj.wordpress.com/2014/02/18/serious-problems-with-the-k-12-senior-high-school-curriculum/, date retrieved: February 18, 2014

Orale, 2016, Senior High School Curriculum in the Philippines, USA and Japan, Research gate, pp.16

Stensmo, 2006, Perceptual Reference In Learning Among Teacher Education Students in Practical Aesthetical Subjects, paper presented at the NFPF conference

Cox, T. D. (2013). Learning Styles and Admission Criteria as Predictors of Academic Performance of College Freshmen. Institute for Learning Styles Journal, 1(1). URL: http://www.auburn.edu/academic/education/ilsrj/Journal\%20Volumes/Spring\%202013\%20Vol\%201\%20PD Fs/Learning $\% 20$ Styles $\% 20$ and $\% 2$

Admission\%20Criteria\%20as\%20Predictors\%20of\%20Academic\%20Performance.pd, date retrieved: November 15, 2013

Joel Tabora, Serious Problems With The K-12 Senior High School Curriculum, URL: https://taborasj.wordpress.com/2014/02/18/serious-problems-with-the-k-12-senior-high-school-curriculum/, date retrieved: February 18, 2014

Gross, Ronald. 2004. Peak Learning. USA. Library of Congress

$\begin{array}{lllll}\text { Felder \& } & \text { Brent. (2005). Understanding Student Differences URL: }\end{array}$ www.4.ncsu.edu/unity/locker/users/Felder/public/Papers/Understanding

Cassidy (2004). Learning Styles and High School Students' Chemistry Achievement. Science Education International Vol. 18, No. 1,

Wong, Linda (2012), Essential Study Skills, 7th Edition

Muhundan (2011). Matching Learning Styles and Teaching Styles in Biology Teaching: An Alternative Approach to Mainstream Science Education in Singapore. URL: http://www.math.nus.edu.sg/aslaksen/projects/Vanessa.pdf

Denig, Stephen J. (2004). Multiple Intelligences and Learning Styles: Two Complimentary Dimensions URL: http://projects.cbe.ab.ca.central/altidul/FILES

Coffield, et.al (2004). Learning styles and pedagogy in post-16 learning A systematic and critical review. URL: http://www.leerbeleving.nl/wp-content/uploads/2011/09/learning-styles.pdf

Abidin, et.al (2011). Learning Styles and Overall Academic Achievement in a Specific Educational System. International Journal of Humanities and Social Science Vol. 1, no. 10, August 2011.

Steedly (2008). Social Skills and Academic Achievement. Evidence for Education, Volume III, Issue 2. URL: http://www.parentcenterhub.org/repository/social-skills/

Akey, T.M (2006). School Context, student attitudes and behaviors, and academic achievement: An Exploratory analysis. New York: MDRC. URL: http://www.mdrc.org/publications/419/full.pdf

Methods of Research and Thesis Writing, p. 62 reprint 2017

Evans, C. \& Waring, M. (2006). Towards teacher inclusive education:Sensitising individuals to how they learn. Educational Psychology, 26(4),499-518).

Crawford, S., Alhreish, S., and Popovich, N. (2012). Comparison of learning styles of Pharmacy students and faculty members. American Journal of Pharmaceutical Education, 76 (10) 1-6. 
Hall, E. \& Moseley, D. (2005). Is there a role of learning styles in personalized education and training? International Journal of Lifelong Education, 24(3), 243-255. URL: http://dx.doi.org/10.1080/02601370500134933.

Sternberg, R., Grigorenko, E. and Zhang, L. (2008). Styles of learning and thinking matter in instruction and assessment. Perspective of Psychological Science, 3(6), 486-506. URL: http://dx.doi.org/10.1111/j.17456924.2008.00095.x

Felder and Solomon, B. 2002, Learning Styles and Strategies, journal of educational psychology, 107

Oxford, Rebecca L. , 2003, Language stykes and strategies: an overview, GALA, 3-4

Higgin, Tanner, 5 classroom strategies that help introverts and extroverts do their best work, URL: https://www.commonsense.org/education/blog/5-classroom-strategies-that-help-introverts-and-extroverts-dotheir-best-work

Ryan Pecson, Localization and Contextualization in Teaching K-12 Social Studies URL: http://ryanramoletepecson.blogspot.com/2014/06/localization-and-contextualization-in.html

Janelle cox, teaching Strategies to Approach Different Learning Styles, URL: http://www.teachhub.com/teaching-strategies-approach-different-learning-styles

Amanda Morin, Personalized Learning: What You Need to Know, URL: https://www.understood.org/en/schoollearning/partnering-with-childs-school/instructional-strategies/personalized-learning-what-you-need-to-know

O'Leary, C., \& Stewart, J. (2013). The Interaction of Learning Styles and Teaching Methodologies in Accounting Ethical Instruction. Journal of business ethics, 1-17. URL: http://link.springer.com/article/10.1007/s10551-012-1291-9, date retrieved January 31, 2014

Bostrom, L., \& Hallin, K. (2013). Learning Style Differences between Nursing and Teaching Students in Sweden: A Comparative Study. International Journal of Higher Education, 2(1), p22. URL: http://sciedu.ca/journal/index.php/ijhe/article/view/2264, date retrieved January 31, 2014

Prabha, V., Geetha, K. B., Doddamani, B. R., Prakash, M., \& Prakash, S. M. (2013). Learning styles among the first year medical students. Int J Pharm, 4(2), 135-139. URL: http://www. pharmscidirect.com/Docs/IJPBR2013-02-154.pdf, date retrieved: January 10, 2014 